\title{
Variations in different polycystic ovary syndrome phenotypes in a population of Chinese Han
}

Rong Huang, Jun Zheng, Shengxian Li, Lihua Wang, Tao Tao, Xiangyu Teng, Jing Ma and Wei Liu

Department of Endocrinology and Metabolism, School of Medicine, Ren Ji Hospital, Shanghai Jiao Tong University, 160 Pujian Road, Shanghai 200127, People's Republic of China
Correspondence

should be addressed

to W Liu

Email

sue_liuwei@163.com

The above article has been retracted. The retraction was made before the article reached its final form in the publication process. However, the authors' accepted manuscript, prior to copy editing, page layout and proofing, was made available online as an Endocrine Connections Accepted Preprint on 20 November 2013.

The article was submitted to the journal in error and retracted at the request of the authors.

http://www.endocrineconnections.org DOI: 10.1530/EC-13-0080
(C) 2014 The authors Published by Bioscientifica Ltd

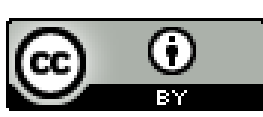

This work is licensed under a Creative Commons Attribution 3.0 Unported License. 